This item was submitted to Loughborough's Research Repository by the author.

Items in Figshare are protected by copyright, with all rights reserved, unless otherwise indicated.

\title{
Strategy narratives and wellbeing challenges: the role of everyday self- presentation
}

PLEASE CITE THE PUBLISHED VERSION

http://dx.doi.org/10.1016/j.jbusres.2015.07.036

PUBLISHER

(C) Elsevier

VERSION

AM (Accepted Manuscript)

\section{PUBLISHER STATEMENT}

This work is made available according to the conditions of the Creative Commons Attribution-NonCommercialNoDerivatives 4.0 International (CC BY-NC-ND 4.0) licence. Full details of this licence are available at: https://creativecommons.org/licenses/by-nc-nd/4.0/

\section{LICENCE}

CC BY-NC-ND 4.0

\section{REPOSITORY RECORD}

Liu, Chihling, Debbie I. Keeling, and Margaret K. Hogg. 2019. "Strategy Narratives and Wellbeing Challenges: The Role of Everyday Self-presentation". figshare. https://hdl.handle.net/2134/18100. 


\title{
Strategy Narratives and Wellbeing Challenges: The Role of Everyday Self-Presentation
}

\author{
Chihling Liu, Lancaster University, UK \\ Debbie Isobel Keeling, Loughborough University, UK \\ Margaret K. Hogg, Lancaster University, UK
}

Submission: April 2015

Revision:

Accepted:

Send correspondence to Chihling Liu, Lancaster University Management School, Charles Carter Building, Lancaster, Room: D36, LA1 4YX, UK, telephone: +44 (0) 1524510197 (Chihling.Liu@lancaster.ac.uk); Debbie Isobel Keeling, School of Business and Economics, Sir Richard Morris Building, Loughborough University, Leicestershire, LE11 3TU, telephone: +44 (0) 1509223117 (D.I.Keeling@lboro.ac.uk); Margaret K. Hogg, Lancaster University Management School, Charles Carter Building, Lancaster, Room: D43, LA1 4YX, UK, telephone: +44 (0) 1524510767 (m.hogg@lancaster.ac.uk). 


\title{
Strategy Narratives and Wellbeing Challenges: The Role of Everyday Self-Presentation
}

\begin{abstract}
How do consumers manage their everyday self-presentation to attain a sense of wellbeing? Through the lens of consumption, this study contributes to understanding the link between self and everyday interactions by identifying and developing a typology of wellbeing challenges and how these are managed in a variety of social contexts. Fifteen phenomenological interviews revealed a series of strategy narratives through which individuals pursue wellbeing within their web of social encounters. These strategy narratives combine in a series of pathways that range from harmonious (e.g., enhancement) to incongruous (e.g., concealment) in individuals' efforts to manage challenges to personal wellbeing. Constructing a typology from these pathways, the research findings pose both opportunities and challenges for social marketers to promote consumers' positive experiences in the marketplace.
\end{abstract}

Keywords: internal narratives, external selves, personal wellbeing, self-presentation, social contexts, strategy narratives 


\section{Introduction}

Advances in cosmetic procedures and self-adornment offerings present numerous possibilities for the presentation and transformation of self in everyday life. These possibilities offer consumers opportunities to conceal, reveal or enhance different aspects of the self, which proves central in defining who they are and how others react during social encounters (Choi, Ko, and Megehee 2014). The perceived quality of these social encounters in turn can profoundly impact consumers' sense of wellbeing (Kaplan 1986). How then do social marketers know how consumers manage their wellbeing experiences through their presentation of self? In addressing this question, this study investigates (1) how consumers' external self-presentation efforts interact with their internal selves within multiple social contexts; and (2) how a sense of wellbeing is managed by their self-presentation choices in social interactions (Lynch 2014). The investigation aims to help social marketers fathom the wellbeing challenges consumers experience within a range of social contexts, and develop programs to support consumers in reexamining their selfpresentation concerns for a more positive self-experience in the marketplace.

Earlier research emphasized that socio-cultural ideologies influence a consumer's inherent meaning system, which directs the different roles that they adopt to cope with the various needs and problems in life (Elliott and Wattanasuwan 1998; Mead 1934). Schouten (1991), for instance, found aesthetic plastic surgery to represent a means of control that enables individuals to restore harmony to an unsatisfactory self-concept, especially during major life transitions (also see Askegaard, Gertsen, and Langer 2002). Belk (2003) discussed the power of shoes in communicating individuals' ideas of the self, including taste, character, cultural capital, social status and information about self-regard. In these terms, an individual treats the self as a symbolic project, which s/he actively carves out from the available resources to seek positive self- 
presentation and self-improvement (Giddens 1991). The seeking of the positive self motivates individuals' consumption behavior and contributes to their personal wellbeing.

Yet, the nature of the wellbeing tasks that individuals face within social encounters is complex. Fredrickson and Roberts' (1997) objectification theory posits that women are typically socialized to present a self that serves to achieve relationship wellbeing. However, in so doing, women are simultaneously subject to mental health risks (e.g., stress, depression) as they tend to prioritize relationship wellbeing over their own personal wellbeing (Piran and Cormier 2005; Szymanski and Henning 2007). Researchers have criticized contemporary marketing and advertising for perpetuating this tendency by portraying women as supporting actors in society (e.g., as secretaries) or emphasizing a feminine construction of health and wellbeing (e.g., normalized representations of female bodies) instead of reflecting the lived experience of women today (Catterall, Maclaran, and Stevens 2000; Gurrieri, Previte, and Brace-Govan 2013). Lynch (2014) thus calls for a more integrative approach to investigating how people’s self-concept is embedded in their social encounters to better understand the potential impact of these encounters on personal wellbeing. This article addresses this call by exploring women consumers' personal narratives to reveal their lived experiences of self and wellbeing within multiple social contexts. Past research indicates that personal narratives could hold the key to understanding how selfpresentation and social interactions are linked (Arnould and Thompson 2005). That is, the choices the consumer makes and her interactions with others are made comprehensible through the process of storytelling (Polkinghorne 1991). The present study thus concentrates on consumers’ personal narratives revealing how personal wellbeing is expressed and pursued by organizing their different self-presentations in a variety of social contexts.

This paper aims to make two substantive contributions. First, this study offers a typology derived from consumer-defined wellbeing challenges and the emergent strategy narratives that 
consumers employ to address such challenges within multiple social contexts. Rather than approaching wellbeing as a measureable outcome of behavior, the present study adopts the informants' orientation of wellbeing as a dynamic process through which their internal and external selves continually interact. Contemporary anxieties about how best to present and define the self in social contexts can thus be expressed in terms of wellbeing challenges. This paper utilizes objectification theory as a basis for understanding the wellbeing challenges that women consumers experience in their dealings with social others. Furthermore, informants' experiences revealed a series of what this study terms strategy narratives that are used to manage these wellbeing challenges. Within an organizational context, strategy has been theorized as storytelling that involves multiple discourses, and acts as guiding principles to facilitate a specific outcome in complex environments (Boje 2010; Küpers, Mantere, and Statler 2013). This study adapts this lens to the wider social context as a way of understanding how consumers address wellbeing challenges to strive for personal wellbeing in a given social encounter. That is, how consumers enact strategies by engaging in the ritualized repetition of specific narratives or stories that they have learnt over time in an attempt to enable a specific, tailored experience of the self. Understanding how self-presentation and social interactions are linked through strategy narratives offers insights into how consumers address their interpersonal concerns and attempt to craft personal wellbeing in different social settings.

Second, this study offers a theoretical specification based on strategy narratives that link consumption to multiple social contexts and wellbeing (Lynch 2014). Specifically, the study identifies how strategy narratives align consumers' internal and external selves along either harmonious (e.g., enhancement) or incongruous (e.g., concealment) pathways. These pathways have profound consequences not only for the management of personal wellbeing but also for the resultant self-consumption experiences. The extent to which women practice or reject self- 
adornment reflects how strategy narratives link aspects of the self to specific wellbeing challenges in everyday interactions. The use of self-adornment among the informants appears to play a central role in transforming or enhancing the way the self is lived in its social encounters (Featherstone 2010; McCracken 2008).

\section{Theoretical foundations}

Objectification theory provides a framework for understanding the link between women’s lived experiences and mental health risks (Fredrickson et al. 1998). The theory postulates that women perform persistent body surveillance (i.e., how they look to others) within interpersonal and social encounters so that they can be "looked at and evaluated" in a positive light to generate a sense of self-worth (Fredrickson and Roberts 1997; Strelan and Hargreaves 2005). Clearly, a close relationship between the external self and life opportunities exists (Lemay Jr, Clark, and Greenberg 2010). Successful cultivation of the external self that satisfies the positive expectations of others can improve an individual's social wellbeing, which is key to attaining personal wellbeing (Stoppard 2014). However, self-objectification can also cause body shame, anxiety and behavioral dysfunctions (e.g., eating disorders) that significantly undermine personal wellbeing. This is especially the case when the individual perceives herself as failing to meet sociocultural standards about the ought self, which leads to acute anxieties (Moradi and Huang 2008). What results is a conflict between personal and social wellbeing. This is because personal wellbeing is a multi-dimensional concept that not only requires positive relations with others but also other defining characteristics such as self-acceptance, self-autonomy, self-efficacy and personal growth (Ryan and Deci 2001). 
The literature on wellbeing, especially with reference to gender, has long emphasized the complex interplay between personal and social wellbeing (Lerner, Hertzog, Hooker, Hassibi and Thomas 1988; Piran and Cormier 2005). This is of particular relevance to women because they are often socialized into the role of a caregiver (e.g., daughter, friend, wife or mother) who puts the needs of others before their own (Jack 1991; Thompson 1996). Indeed, women often derive a sense of the positive self from their ability to enter and maintain close relationships (Kaplan 1986). Yet, they often do so by suppressing negative feelings and their own needs during social interactions (Lerner et al. 1988; Piran and Cormier 2005). The emphasis here is on concealing the negative self that is perceived to be in conflict with social expectations in order to achieve relationship wellbeing. The tendency to conceal the self in social interactions can prompt depressive symptoms, negative self-esteem and psychological distress (Larson and Chastain 1990; Vogel, Heimerdinger-Edwards and Hubbard 2011). For example, Lerner, Hertzog and Hooker (1988) illustrated how self-concealment in a given social encounter often leads to internalized anger. In the consumption context, Hartman, Patock-Peckhama, Corbin, Gates, Leeman, Luk and King (2015) found that greater self-concealment was linked to impaired selfcontrol over drinking, thereby threatening personal wellbeing. The tendency to perform selfconcealment can thus be an enduring struggle between personal and social wellbeing pursuits.

Wellbeing pursuit is a form of narrative that consists of distinct pathways of striving for personal wellbeing (Bauer, McAdams, and Pals 2008). Narrative is a way of understanding human relationships and the different pathways individuals follow in relating the self to the outside world (Boland and Tenkasi 1995). For example, Bauer et al. (2008), focusing on wellbeing, found narratives that underline intrinsic motivation guide individuals in developing their inner strengths and virtues. In contrast, narratives that emphasize extrinsic motivation guide individuals to pursue social approval, status and the achievement of certain physical appearances 
(e.g., the presentation of a successful image to others and to the self). In these terms, different narrative pathways appear to embody distinct strategies that individuals use to guide everyday interactions and manage their wellbeing. We conceptualize the different pathways through which a consumer tells her wellbeing stories by adopting the lens of strategy as storytelling to study how consumers manage challenges to their wellbeing (cf., Küpers et al. 2013). These different narrative pathways characterize the distinct strategies the consumer adopts to situate herself meaningfully in relation to her specific social others. Importantly, the present study argues that

through strategy narratives the consumer constructs and reproduces social interaction dynamics to make sense of what roles she does, can or should play to achieve a sense of wellbeing.

This article thus seeks to identify and define wellbeing from the perspective of individual consumer experience in the face of a variety of interactional demands. The study illustrates how women experience wellbeing as a series of definable challenges and identifies the emergent strategies of wellbeing management. The study also demonstrates that the informants experience strategy as a series of narratives determining different pathways towards personal wellbeing. Importantly, the emphasis is on how consumption, self-adornment in this case, manifests itself in these pathways and the impact on consumers' sense of wellbeing. This research yields important implications for social marketers who share an interest in understanding consumers' marketplace experiences in order to better promote their sense of wellbeing in the context of everyday lives.

\section{Method}

This study adopts an existential phenomenological approach to explore how individuals manage their sense of wellbeing within multiple social contexts, with specific reference to the emergent strategy narratives around self-adornment. For Heidegger (2010), the construction of 
meanings about the self always involves the existence of other people, what he terms intersubjectivity. The present study shares this focus on intersubjectivity, and explores the significance of the relationship between self, social interactions and cosmetics consumption.

The intricate relationship between the manipulation of the external self-presentation and the successful endorsement of life politics is well documented (Giddens 1991). In line with feminist literature that has revisited the link between self and artifice (Scott 2006), this study treats self-adornment practices as an important means for women to manage wellbeing challenges during social encounters. That is, the study seeks to gain an understanding of how personal wellbeing is managed in a given social context by investigating the interpersonal dimension of women’s external self-presentation. The present research chose cosmetics as the empirical context because the product category is central to women's consumer culture, represents an essential, yet mundane, means of self-reinvention and transformation, and allows women to articulate different aspects of the self at ease, including both positive and negative (Coulter, Price, and Feick 2003). In addition, unlike more dramatic measures such as plastic surgery (Askegaard et al. 2002), the temporal and noninvasive nature of cosmetics allows an investigation of the daily management of the self in response to a variety of interactional demands.

As such, the key criterion for informants' selection for this study was women who consume cosmetics on a daily basis. Fifteen women were recruited for individual interviews in two phases: firstly, through personal contacts, and secondly, through informant referrals. It is important to note that the current study is not limited to a woman's lived experience of how cosmetics are utilized to manage wellbeing challenges. The study encompasses other elements of self-adornment practices (e.g., clothes, hair) spontaneously reported by the informants as a way of facilitating desired interaction. The unstructured phenomenological interviews (Thompson, Locander, and Pollio 1989) were conducted by the first author, audio recorded and transcribed 
verbatim, producing an average of 11,000 words per transcript. Each interview ranged between 12 hours and began by asking the informant's thoughts about cosmetics as a means to aid her narrative of the role that her external self plays in facilitating social intercourse. Body language, facial expressions and tone of voice (e.g., apologetic laughter) were also noted to ensure that this study captured, as far as possible, the authenticity of each informant's account (Maxwell 1992). In line with prior research (Thompson 1997), this research uses the hermeneutic circle as an analytical tool to constantly attain new insights and revise interpretations of the text on its own terms (Cross and Gilly 2014). The term hermeneutic circle refers to understanding the whole in relation to the details, and the details in relation to the whole. The text of each individual is studied with a pre-understanding of the historical and cultural background (= the whole) within which the specific text in question (= the part) resides (Debesay, Nåden, and Slettebø 2008; Thompson 1997). This continual circular movement leads to an evolving understanding of the research phenomenon as a whole (table 1). This study used the resulting understanding to develop a theorized storyline grounded in and driven by the empirical data (Gioia, Corley, and Hamilton 2013; Hogg and Maclaran 2008), as demonstrated in the next section.

\section{TABLE 1 HERE}

\section{Managing personal wellbeing within social relationships}

The informants in this study expressed wellbeing as an ongoing and dynamic process that required constant management. Judging from the informants' use of language in describing their experiences, they saw this management process as a daily challenge that they faced in deriving a sense of wellbeing from their web of social encounters (e.g., "I should make an effort to...”; “I 
am worried if I don't...”). We propose a 2x2 matrix (table 2) based on the emergent informantdefined wellbeing challenges.

\section{TABLE 2 HERE}

These challenges emerge as an interaction between two dimensions. The first dimension defines whether the individual's wellbeing management is focused on herself or a specific other(s). That is, whether the focus of consumption is to influence how the individual carries herself or on how other people react to her during a social interaction. The second dimension defines whether wellbeing management is intended to conceal the negative self or enhance the positive self in a given social interplay (table 1). Drawing on the informants' lived experiences, this study differentiated wellbeing in terms of the challenges of self-avoidance, survival, selfadvocacy and intimacy. The management of wellbeing challenges is enabled and sustained through a series of strategy narratives (i.e., a set of guiding principles that manifest and structure different pathways). These narratives simultaneously produce meanings that drive different selfconsumption experiences depending on which pathway is engaged.

However, like Fredrickson and Roberts (1997), this study acknowledges and emphasizes that the extent to which women experience and manage wellbeing challenges is rather fluid and context dependent. This study recognizes that unique combinations of age, class, ethnicity and physical and personal factors will produce diverse sets of wellbeing experiences in the face of interactional demands. Yet, the present research argues that, to the extent that particular social contexts become salient, certain types of wellbeing challenges tend to ensue. On a micro-scale, women enter into and exit from multiple contexts over the course of a day. Some contexts may trigger their desire to conceal the negative self, and some may motivate them to focus more strategically on enhancing the positive self. Although this study should ideally address women's concealment of the negative self and enhancement of the positive self concurrently, informants' 
accounts suggest that these intentions reflect not only distinct wellbeing challenges that tend to occur in specific social settings, but also the strategy narratives they often embrace to achieve wellbeing in response to these challenges. In the following sections, this article describes and analytically distinguishes these wellbeing challenges and their corresponding strategy narratives (Thompson, Pollio, and Locander 1994). Finally, the study reflects on the boundary conditions of self-adornment for self-concealment and self-enhancement.

4.1 The wellbeing challenge of self-avoidance

The challenge informants experience here is to maintain a sense of wellbeing through avoiding aspects of the negative self (Ogilvie 1987). The study elicited two streams of strategy narratives as salient to achieving self-avoidance: (1) the strategy narrative of compensating the self, and (2) the strategy narrative of rejecting a specific self-dimension.

\subsubsection{The strategy narrative of compensating the self}

Ruth: There were times when I just needed that confidence [by wearing makeup \& dressing up]. I'm not naturally gifted in exams; I think I was a slow learner. I think it's the people around you as well were more clever so that used to get me down. (Age 29, graphic designer)

A perceived academic inadequacy has thrown Ruth into a rather negative sense of the self in relation to the "clever” ones in the school context. Ruth's self-adornment practices here underscore her attempts to navigate herself away from the negativity, to protect an overall 
positive sense of self-worthiness (Crocker and Luhtanen 2003). Ruth uses her makeup transformed self as a confidence boost (e.g., attractiveness) to compensate for her sense of unworthiness resulting from the perceived academic inadequacy. Likewise, Jordan describes how she adorns herself to compensate for the fact that she was brought up without a mother, and that she had been treated as a "tomboy" during her childhood.

Jordan: Don’t forget I didn’t have a mum, so I was brought up with my dad, and we could never watch girly things on the telly...He used to have my hair cut like a bowl was put on it...When I left home, the hair come down here, the makeup was on, everything...I wasn't a feminine looking person up to when I started, probably 15. Up to then I was always a tomboy, so I never looked a girly girl... (Age 57, cashier for supermarket)

Throughout Jordan's interview dialogue, she repeatedly emphasized the criticality of adorning herself when stepping out of the house as a way of expressing her femininity. This experience is in stark contrast to that of her childhood where her father largely restricted her selfadornment practices, and she perceived herself as lacking in femininity. Engaging in selfadornment practices seems to be Jordan's way of compensating for the undesired sense of self in relation to other people experienced during her teens (e.g., being treated as a "tomboy”, unattractive to boys, and having an authoritarian dad). The makeup self represents her transformed self and symbolizes her desired form of social interaction with others (e.g., she goes on to describe being an attractive woman and how this helps her bonding with her daughters).

\subsubsection{The strategy narrative of rejecting the self}


Joyce: I just feel like I'm myself when I've got it [Rimmel fake tan] on, which is a really sad thing to say. I feel really ugly when I'm not wearing it. (Age 20, receptionist)

Valeria: I’m “me” as long as I’ve got makeup on. (Age 31, accountant)

Joyce and Valeria’s experiences are not uncommon among the women in this study, with their strong focus on rejecting the unadorned self through acts of self-adornment. The unadorned self is apparently closely linked to experiences of self-disgust, self-loathing and even shame (Lewis 1995). For Joyce and Valeria, the rejection of the unadorned self is seemingly a defense mechanism assumed for ego-protection. That is, these women perceive the unadorned self as socially undesirable, as the Western cultural tradition emphasizes the importance of physical attractiveness in social perception and interpersonal attraction (Charon 2009; Mead 1934). As a result, Joyce and Valeria appear to be addicted to their transformed self to the extent that they no longer acknowledge their unadorned self. The self in an unadorned state becomes something they dislike, an aspect of something they deny about who they are, and something they perceive as the inauthentic self (Hilgard 1949). This understanding explains why the unadorned self often leads to interpersonal difficulties, as Alice comments, “I just kept my head down and didn’t speak to many people and wasn't very talkative. It just puts me in a mood [when I'm without makeup in front of others].” Overall, these informants utilized self-adornment practices as an instrument to actively reject the undesired self-being-in-the-world.

The strategy narrative of rejecting the self in this study can be further evidenced in other specific contexts, which highlights the prevalence of this strategy narrative adopted by the informants for a wide range of relationship transformation purposes. For example, for Lisa, who is mixed-raced, hair extensions have instrumental values in allowing her to reject aspects of the 
self that are "black" (e.g., natural curly hair), and transforming the self into what she perceives as desired by the dominant “white” culture (e.g., straight hair). In Janet’s account, she uses makeup to reject the aging self, in order to feel "normal" and prevent her self from falling into an undesired social interaction (e.g., being treated as an older person, the perceived abnormal self in relation to others). In sum, these women seemingly tirelessly perform these everyday selfadornment practices for the purpose of rejecting a particular dimension of the self in order to achieve what they perceive to be a more existentially fulfilling experience (Lemay Jr et al. 2010).

\subsection{The wellbeing challenge of self-advocacy}

The challenge informants experience here is to advocate the positive aspects of the self in order to enhance personal wellbeing in social interplays (Lyubomirsky, King, and Diener 2005). Two streams of strategy narratives emerge from the informants' accounts: (1) the strategy narrative of cheering up the self, and (2) the strategy narrative of empowering the self. Whereas the underlying intention of the strategy narrative associated with the self-avoidance in theme one is to hide aspects of the self in a given social context, in contrast, self-advocacy is about enhancing aspects of the self in everyday interactions.

\subsubsection{The strategy narrative of cheering up the self}

Sarah: I think if I went out [without makeup, doing my hair] I wouldn’t be as chatty to people. I'd rather stay in my own little space...I feel personally happier when I've got makeup on and I can engage with people better. (Age 50, cleaner) 
For the informants, there is a seemingly clear distinction in their affective experiences between the adorned self and the unadorned self. Sarah’s description above demonstrates this. Here Sarah (like other informants) utilized self-adornment practices as a means of inducing positive affect, enabling her to be pro-social and manage life challenges. That is, the adorned self brings about a positive affect that in turn enables these women to facilitate social connectedness, goal-directed behaviors, and positive interaction with the outside world, ultimately leading to potential successful life outcomes (Larsen 2000; Lyubomirsky et al. 2005). Indeed, for these women, positive affect begets success, and success makes them happy, which further strengthens the desired self-world relationship. In a more private context, Linda describes the positive effect of self-adornment on her sense of self in the following passage.

Linda: I think even if I wasn’t going out to meet anybody particular or no one is gonna see me, I think you still like to feel, get that picture in your own mind, because you can’t see so you put something on and picture that's you, that's your identity. I've dressed because, for me, I do like to put different things on, your mood changes from what you want to wear. (Age 56, administrator)

The self-adornment experience here represents Linda’s relationship with her self, or with her real or imagined, present or anticipated relational others, and she employs her self-adornment experience in pursuit of her fantasies, mood changes, and fun (Holbrook and Hirschman 1982). By adorning the self in variegated ways here, Linda is able to enhance her self in different dimensions, and engage in explicit forms of identity play. Self-adornment for the informants not only serves to create a good impression on others and elicit their approval, but also acts to regulate self-feelings, actively transforming their psychological and mood states. 


\subsubsection{The strategy narrative of empowering the self}

Isobel: because I was a lot tougher with makeup, I acted a certain way, it did make me feel more ready, like, I was, kind of, more stronger, in a way, I had empowerment...it helped me cope [with being black at school], it helped me keep my personality. (Age 27, social worker)

Isobel's skin color, which differs from the majority in her school context, seems to endow her with a sense of inferiority, pose a major threat to her sense of wellbeing, and undermine her ability to show her perceived authentic self that is tough and strong. Indeed, for Isobel, cosmetics were what allowed her to cope with being different at school, maintain her perceived inherent personal characteristics, and interact with others (cf., Schouten 1991). Isobel is thereby able to cultivate her desired social interactions in the school context (e.g., not be teased and/or bullied). Similarly, Linda narrates how she uses her adorned self as a way of coping with her rather introverted self, “it's (physical appearance) like a book, the front of the book but you've not read the story. Sometimes you'll pick a book because it looks interesting.” To Linda, her physical appearance is like the front of a book, and her personality is somewhat analogous to its contents waiting to be discovered. A book's front cover that appears interesting will prompt people to keep reading page after page. Likewise, by decorating her external self, Linda strives to attract people to know her as a person, which empowers her during social encounters.

\subsection{The wellbeing challenge of intimacy}


The challenge informants experience here is to create intimacy between parties to produce a higher, more positive sense of wellbeing (Fehr 2004; Helgeson, Shaver, and Dyer 1987). The intimacy is created through the enactment of two streams of strategy narratives: (1) the strategy narrative of caring for others, and (2) the strategy narrative of bonding with others.

\subsubsection{The strategy narrative of caring for others}

Joanna: Mark, my partner, he doesn’t want me to see me like that either [big eyelashes, big hair, loads of brushers, loads of red lipsticks, really like slutty looking]. Because I think he would think like why she is wearing that much makeup because she has got me, does she want to attract other people? (Age 26, researcher)

Talking about changes in her makeup patterns, Joanna illustrated how her makeup use has been toned down to care for her partner's feelings, and to reassure him that she is loyal to the relationship. As such, she is able to foster the desired intimacy and trust between them. In contrast to Joanna's experience here, Nancy (age 55, personal assistant) consumes more makeup instead as a means of caring for her partner in the public arena, as she comments, "I would want to look attractive for him, to other people; to show that he is with an attractive woman”. In consuming more makeup, Nancy attempts to not only cultivate the desired self in relation to her partner, but also enable her partner to attain a more desired state of self in relation to others (e.g., I am with an attractive woman).

Joanna's and Nancy’s contrasting ways of caring for their loved ones highlight the diversity of human experience in managing social encounters. Indeed, whereas Joanna and Nancy differ in their approach to showing that they care, they appear to both anticipate somehow 
enhanced appreciation from their partner as a result. The anticipated increase in appreciation in turn further reinforces their chosen approach of caring for their loved ones. The present research also noted the strategy narrative of caring for others in a professional context:

Sandra: I used to do some mentoring and if I am mentoring someone who is unemployed, I will make a point of wearing very little makeup [and more casual clothes]...I don’t want them to feel threatened in anyway. (Age 30, auditor)

Clearly, Sandra tones down her makeup to show her care towards those whom she perceived to be vulnerable. In so doing, she is able to communicate with them at "the same level”, which in turn nurtures a certain degree of intimacy that enables her to be a mentor in a more effective and humane fashion.

\subsubsection{The strategy narrative of bonding with others}

Jordan: It brings you closer to people, doesn’t it? It’s that bonding session you have with your siblings [being pampered by her sister], which helps you as a person to develop. (Age 57, cashier for supermarket)

For Jordan, cosmetics can be a channel used to bring people closer. The makeup sessions attain deeper personal meanings by helping Jordan as a person to develop in domains like family values, people skills and a sense of who I am/am not. In contrast to Jordan's experience of cosmetics as a bonding mechanism, in the following passage, Betty describes her experience of bonding with others through the act of makeup removal: 
Betty: I know a few girls...there’s absolutely no chance to let somebody see them without makeup on...It would be nice if they were comfortable to show themselves without makeup...because it's like without a mask and it's like you getting to know them more... (Age 27, admission officer and event assistant)

For Betty, self-disclosure is the defining element of intimacy in a social interaction (Laurenceau, Barrett, and Pietromonaco 1998; Mashek and Aron 2004). Betty’s account, commonly shared among the informants, exposes that the willingness to reveal the untransformed self shows a profound sense of trust in the socializing other(s) (that the self is unconditionally accepted). It is this trust that liberates the self, and nurtures growing intimacy between parties. Like Jordan's cosmetics use, makeup removal here is also experienced as a bonding mechanism, because it evidently facilitates feelings of authenticity in a social interaction, mutual trust (e.g., I trust that you will not judge my undisguised self, and you appreciate that I trust you as such) and/or an increasing sense of existential meaningfulness. For example, Ruth (age 29, graphic designer) comments, "I use a lot less makeup [being in a relationship] because he [my partner] gave me that confidence and assurance that I didn't need as much”.

4.4 The wellbeing challenge of survival

The challenge informants experience here is to strive for survival during difficult interpersonal or social circumstances (Mead, Baumeister, Stillman, Rawn and Vohs 2011; Stillman, Baumeister, Lambert, Crescioni, DeWall and Fincham 2009). The striving for survival is evidenced in two streams of strategy narratives: (1) the strategy narrative of fitting in with 
others, and (2) the strategy narrative of misleading others. In comparison with the underlying intention of the strategy narrative for creating intimacy, which is to have a deeper connection with others, the underlying intention for the survival narrative is to defend the self from potential existential threats (e.g., ridicule, relationship breakdown).

\subsubsection{The strategy narrative of fitting in with others}

Jennifer: Started [wanting to change certain aspects of myself] at primary school, [I] got moved to another half the year to a group of girls that was kind of new and then ended up probably four years there would be instances of bullying; because I had an older brother who had red hair, ginger, he couldn’t defend me because he was getting bullied even more severe than what I was kind of getting bullied and I would defend him, but then I was in the popular group (I wore makeup as a mask to fit into this group), they would be against me and call in my brother to me and then say you're all XXX. (Age 29, school teacher)

Jennifer's makeup use here appears to be a way of transforming her social status into being part of “the popular group”, in seeking to avoid instances of bullying in the school context. Besides, the personal meanings inherent in her makeup use attain a deeper level of complexity, as Jennifer utilizes the makeup transformed self not only for self-protection, but also for otherprotection (e.g., protecting her older sibling who is teased and taunted for having "red hair"). The self-transformation reveals Jennifer's enduring attempts at altering the undesired social dynamics (e.g., ridicule) for both self and her older sibling, in a bid to survive at the time. 
Jordan: Because I was young to get a job, I needed to look older [when she was a teenager]. My way of looking older was to put the makeup on so I can also get into the clubs and the pubs. (Age 57, Cashier for a large supermarket chain)

Like Jordan, many of the informants in this study expressed how makeup was used to their advantage to fit into the adult world during their teenage years (e.g., Jordan: “if I wore makeup, I was one of them”). Indeed, makeup in this case is used as a means of fitting into a particular social group to prevent the self from being exposed during wrongdoing (e.g., job hunting and/or nightclubbing when not allowed to), and cultivating desired social interplays (e.g., being treated in the same way as those who are older) (Mead et al. 2011).

\subsubsection{The strategy narrative of misleading others}

Sandra's account below describes how her makeup use is varied to mislead others about the self, in order to "either attract or push people away":

Sandra: You can go on a date with someone you don’t like...I will make sure that my makeup does not look spotless that day. I don't know maybe I'll go as far as putting the wrong eye shadow on. (Age 30, auditor)

Apparently, Sandra deters those whom she perceives to be unsuitable romantic partners by intentionally wearing the "wrong" makeup, in an attempt to create an aura of negativities around their social interaction. In these terms, the "wrong” makeup is deployed as a means of 
conveying the unspoken message that “I am not interested”. In the next excerpt, Lisa commented on how makeup is applied to mislead her partner into believing in the otherwise non-existent self:

Lisa: It was annoying that I have to get up a bit earlier to go and do my makeup in the bathroom. But I felt almost like I was winning because I was...not lying to him but I was cheating. It was almost like I was kind of tricking him... And like yeah, because he thinks this is how I look. So it almost felt like a victory. (Age 27, communications manager)

Lisa closely associates her makeup experience here with her longing for the desired interaction between self and her partner (e.g., sexual attraction). The perceived ability to "trick" her partner (enabled by hiding in the bathroom to apply makeup) provides Lisa with an increased sense of self-efficacy (e.g., “winning”; “a mini victory”), and confidence in the love relationship. Yet, while the successful implementation of the "trick" allows Lisa to construct the desired love relationship, simultaneously she feels restricted in her sense of self-autonomy (e.g., "It’s annoying that I have to get up a bit earlier"). That said, it is a cost that Lisa is willing to pay, in exchange for the ability to eliminate potential relationship threats (Rawn and Vohs 2011).

4.5 The boundary conditions of self-adornment for self-concealment and self-enhancement

Joanna's account below demonstrates the perceived boundary condition of self-adornment in concealing undesired aspects of the self in relation to others, when the reality and the desired state of self are in great conflict (Higgins 1987). 
Joanna: So I've been at the hospital that day and it was a really horrible day because it's the first time my dad refused to eat since he got cancer... and then I was meant to be going out with my friends for a night out and I've put on my makeup and I've done my hair and then I just looked into the mirror, I just got really upset about what has gone on, I cried, and obviously ruined my makeup then I felt crap and I didn’t wanna go out but yeah sometimes I suppose you know your makeup can’t cover up everything that's going on in your life. (Age 26, researcher)

In this portion of dialogue, Joanna explicitly utilized self-adornment practices as a temporary escape from the harsh reality that her late father had been in a critical condition in hospital. Joanna focuses strongly on concealing an aura of negativity around the self-father interaction, and restoring a sense of normality in life, at this very turbulent time. Indeed, she used self-adornment practices to “cover up” major traumas in life (e.g., father’s illness), which, according to Joanna's past experience, would always enable her to transform the perceived negative state of the self-being-in-the-world. Nonetheless, her transformed self here clearly failed to help her escape from the negative state, owing to the sharp contrast between the reality and the desired state of self that could not be amended by "a bit of makeup” or "going out". Overall, although Joanna endeavored to perform acts of self-adornment to hide the undesired reality (e.g., “I tried to put on makeup to cheer myself up, to mask what's going on and going out"), she could not "go through" with the transformation to embrace an altered reality as she usually did; as she later comments, "I just felt a bit wrong putting on makeup and going out and enjoying yourself, your dad is dying in the hospital, it felt all a bit wrong and I just got upset about myself."

In contrast to Joanna’s account, Emily’s description below reveals the perceived boundary condition of self-adornment in enhancing aspects of the self in everyday interactions, when Emily 
sees the adorned self as a source of distraction for the goal(s) she attempts to achieve (cf., Gollwitzer 1999).

Emily: If I'm in a situation when I was doing my exams...I'd never wear makeup because at that point, my focus was for questions they’re gonna ask me...I just think not wearing makeup makes me feel like my focus is on other places. Whereas when I've got makeup on, I feel like “yeah, world, this is me, see me now”... I'm ready to socialize; I'm ready to have a conversation. (Age 25, accountant)

Clearly, Emily’s experience of self-adornment represents her goals to impress, obtain approval and engage with the world. Yet, these goals conflict with the need to stay focused on specific tasks that require her full attention without being distracted by social and interpersonal affairs, as Emily’s adorned self evidently prompts her into becoming “Emily-who is socializing”. The presence or absence of the adorned self determines the boundary of which aspects of the self to enhance (e.g., socially oriented versus task-oriented self). In a similar but distinct manner to Emily’s experience, Ruth, states in the context of traveling, "I just had very comfortable clothes, very practical stuff on [when I was traveling], because the priority was experiencing it without focusing on what I looked like really.” Noticeably, both Emily and Ruth are conscious of how self-adornment draws a boundary between the enhancement of different aspects of the self.

\section{Discussion and conclusion}

The research findings enrich and extend objectification theory and emphasize women’s acute sensitivity to the interpersonal aspects of self-presentation, albeit to varying degrees, and 
the impact of this on their overall sense of wellbeing (Fredrickson and Roberts 1997). In enriching objectification theory, this study offers a typology that encapsulates how consumers experience wellbeing in terms of challenges. The study also introduces the concept of strategy narratives that link the ways in which women manage their wellbeing challenges in specific social contexts to distinct experiential consequences (within a Western culture that advocates the importance of physical appearance). Women's self-adornment practices emerged, in this study, as an integral part of understanding how the positive or negative self is encountered and managed within multiple social settings, which has clear implications for their sense of personal wellbeing. This understanding aids the investigation of the links between specific situations and the associated experiential consequences and mental health risks that objectification theory advances (Fredrickson and Roberts 1997; Moradi and Huang 2008). The typology demonstrates an understanding of how consumption may be manifested within the context of wellbeing (in the present research context of self-adornment; figure 1). The typology is not meant to account for all variations in the wellbeing challenges that women may face in social interactions. Rather, the typology represents a snapshot of how women may manage the self during social encounters as a starting point, grounded in the empirical data, upon which future research can build.

\section{FIGURE 1 HERE}

In the typology of wellbeing management, this study offers a 2-dimensional framework to understand consumers' challenges to managing their personal wellbeing in a range of social contexts. Importantly, the typology places emphasis on the experiences inherent in consumers’ dealings with their wellbeing challenges rather than the coping mechanisms per se that they may draw on to tackle each wellbeing challenge. These wellbeing challenges, defined as survival, selfavoidance, self-advocacy and intimacy, derive from an interaction between the two dimensions illustrated in figure 1 . The informants in this study managed these challenges through their 
strategy narratives. In the social context of interpersonal interaction, it was clear that the research informants experienced these strategies as actively and creatively crafted narratives. The dynamic and transitional nature of these narratives leads the individual down different pathways in response to a variety of interactional demands. These findings corroborate and broaden recent literature on how wellbeing is achieved through different personal "growth stories” driven by intrinsic or extrinsic rewards (Bauer et al. 2008), and prior work that emphasizes the why of consumption for understanding managing the self in everyday interaction (Askegaard et al. 2002; Thompson and Hirschman 1995; Tian and Belk 2005).

The research findings further illustrate how different narrative pathways direct and frame individuals’ consumption experiences. What was evident is that consumers experience these pathways in what this study terms harmonious and incongruous ways. A harmonious pathway underlines consumption as something that enables self or other enhancement or care (related to the wellbeing challenges of self-advocacy and intimacy and associated strategy narratives). In contrast, the incongruous pathway highlights the important role of consumption in assisting the individual with self or other concealment or deception (related to wellbeing challenges of selfavoidance and survival and associated strategy narratives). In sum, the harmonious pathway of managing wellbeing challenges places the emphasis on the development of consumers' positive self or inner strengths and virtues in enriching personal wellbeing during social encounters. The incongruous pathway, on the other hand, draws attention to the importance of concealing or transforming the negative self that does not satisfy perceived social expectations in preventing a sense of ill being (Fredrickson and Roberts 1997; Ogilvie 1987).

Although informants evidently derive a sense of personal wellbeing from the concealment or transformation of the negative self, they appear to simultaneously experience profound 
anxieties as to the danger of failing to do so. For example, in the strategy narrative of rejecting the self, the untransformed self becomes something they hate or avoid, threatening their personal wellbeing. This explains why when informants fail to reject their undesired aspects of self in a given social context, it can be quite detrimental, fostering a profound sense of helplessness or despair (Polkinghorne 1991). These findings add to the growing literature that has identified the powerful role of the undesired self in driving consumption choices by showing the wellbeing repercussions of such consumption choices (Bahl and Milne 2010; Hogg, Banister, and Stephenson 2009). In so doing, this study also extends and complements the work on the wellbeing consequences of self-concealment, especially in the consumption context (Corrigan, Watson, and Barr 2006; Hartman et al. 2015). The findings offer support for objectification theory and provide further useful insights into how women's wellbeing experiences can differ in meaningful ways when confronted with situations in which they tend to focus their efforts on either the concealment of their undesired aspects of the self or enhancement of the positive self.

In addition to these theoretical contributions, the research findings yield important implications for social marketers as to how to better promote consumers' positive experiences in the marketplace. These findings pose challenges to the ways in which such promotion should be conducted, especially in the research context of cosmetics consumption. Cosmetics commercials have long exploited and fostered women's fear of not satisfying social expectations by advocating airbrushed images of models as the standard of beauty (Gulas and McKeage 2000; Richins 1991). However, recent cosmetics marketing campaigns are increasingly focused on developing women's sense of self-worth as it relates to their physical appearance in an attempt to be authentically inspiring. One example is Dermablend Professional, a brand of corrective cosmetics designed for people with skin conditions (e.g., severe acne, vitiligo). In their 2014 campaign they put a twist on the natural beauty trend by showing how women take off their 
makeup to embrace their flaws, while simultaneously using makeup to enhance who they are. The strategy narratives this study presents contribute to this marketing wave of wellbeing promotion. In support of Dermablend Professional's approach, the strategy narratives indicate the importance of encouraging consumers towards a harmonious pathway of wellbeing management. This harmonious pathway addresses wellbeing challenges by focusing on enhancing consumers' positive self in social intercourse, and not on concealing or transforming their perceived negative self as promoted by the incongruous pathway of wellbeing management. In many respects, cosmetics advertisers have urged consumers to draw on the incongruous pathway of wellbeing management by marketing their products to consumers' negative feelings of self in order to create a want or need. For instance, Clinique’s marketing campaign utilized a speckled egg to represent imperfect skin conditions that need to be concealed or transformed. As this study has argued, self-concealment can cause a negative impact on women's personal wellbeing, especially in the long term (Larson and Chastain 1990; Vogel et al. 2011).

To advance consumers' wellbeing, a first step would be to run educational programs to raise the awareness amongst girls and women of the range of social contexts likely to elicit attempts to conceal the self and the adverse impact these self-concealment attempts can have on their mental health. Such increased awareness, in turn, could motivate girls and women to focus more on the self-enhancement aspects of their self-presentation even in situations where desires to conceal the self tend to surface. That is, a change in the mindsets can create resilience in the face of threatening social settings (e.g., needs to fit in to stop bullying) (Yeager and Dweck 2012). While feminist activists have certainly already made varying attempts to improve women's welfare, the present work continues Fredrickson and Roberts' (1997) call for the need to intervene early and often in the prevention of women's tendency to conceal the self during their encounters with others (Larson and Chastain 1990; Vogel et al. 2011). 
However, the research findings should be applied with caution as the interplay between consumers' positive and negative selves is complex and delicate, and is worth further investigation. For example, commentators have heavily criticized Dove’s real beauty campaign for being highly selective in choosing which so-called real women to present (Johnston and Taylor 2008). In addition, in the present study, some informants define the adorned self as the empowered self without which they lose their preferred personality and encounter their negative self. The research findings show that there is an intricate interplay between informants' desire for physical attractiveness and wellbeing. Yet, prior research has suggested that people can be highly selective in terms of the domains on which they stake their self-worth and achieve wellbeing (Crocker and Luhtanen 2003). For some people, self-worth is largely dependent on their physical attractiveness (e.g., extrinsic motivation); for others, self-worth may be derived more from being true to the self within social interactions (e.g., intrinsic motivation) (cf., Bauer et al. 2008). Future research could compare the potential differences between people who tend to stake their selfworth on how they look and those who do not (e.g., women who do not wear cosmetics), and how they manage their wellbeing challenges within multiple social contexts. Specifically, an investigation of the potential differences in the 'contents' of the positive and negative selves experienced during social encounters is a promising approach to painting a fuller picture of the different pathways that consumers follow in managing daily wellbeing challenges.

Beyond self-adornment practices, this study provides food for thought on how other forms of consumption, especially in the domain of self-care (e.g., food, exercise and personal space decoration), can be utilized to manage personal wellbeing during social encounters. Furthermore, past researchers have shown that perceived qualities of friendships and romantic relationships have a differential impact on emerging adults' (ages 18-26) identity development (Barry, Madsen, Nelson, Carroll and Badger 2009). An investigation into wellbeing challenges and their 
corresponding strategy narratives in the context of specific social relationships should shed further light on consumer wellbeing management. Finally, as the present study looks at women’s lived experiences, future research may explore how men as consumers experience and manage their wellbeing challenges within social situations. This type of research pursuit would provide a more complete picture of how men and women compare on wellbeing management; and the different gendered views of self-worth in a variety of social interactions. 


\section{References}

Arnould, Eric J and Craig J Thompson (2005), "Consumer Culture Theory (Cct): Twenty Years of Research," Journal of Consumer Research, 31 (4), 868-82.

Askegaard, Søren, Martine Cardel Gertsen, and Roy Langer (2002), "The Body Consumed: Reflexivity and Cosmetic Surgery," Psychology \& Marketing, 19 (10), 793-812.

Bahl, Shalini and George R Milne (2010), "Talking to Ourselves: A Dialogical Exploration of Consumption Experiences," Journal of Consumer Research, 37 (1), 176-95.

Barry, Carolyn McNamara, Stephanie D Madsen, Larry J Nelson, Jason S Carroll, and Sarah Badger (2009), "Friendship and Romantic Relationship Qualities in Emerging Adulthood: Differential Associations with Identity Development and Achieved Adulthood Criteria," Journal of Adult Development, 16 (4), 209-22.

Bauer, Jack J, Dan P McAdams, and Jennifer L Pals (2008), "Narrative Identity and Eudaimonic Well-Being," Journal of Happiness Studies, 9 (1), 81-104.

Belk, Russell W. (2003), "Shoes and Self," Advances in Consumer Research, 30, 27-33.

Boje, David M (2010), Storytelling and the Future of Organizations: An Antenarrative Handbook, London, England: Routledge.

Boland Jr, Richard J and Ramkrishnan V Tenkasi (1995), "Perspective Making and Perspective Taking in Communities of Knowing," Organization Science, 6 (4), 350-72.

Catterall, Miriam, Pauline Maclaran, and Lorna Stevens, eds. (2000), Marketing and Feminism: Current Issues and Research, Oxon: Routledge.

Charon, Joel M, ed. (2009), Symbolic Interactionism: An Introduction, an Interpretation, an Integration, 10th Edn. , Englewood Cliffs, NJ: Prentice Hall. 
Choi, Hyeonyoung, Eunju Ko, and Carol M Megehee (2014), "Fashion's Role in Visualizing Physical and Psychological Transformations in Movies," Journal of Business Research, 67 (1), 2911-18.

Corrigan, Patrick W, Amy C Watson, and Leah Barr (2006), "The Self-Stigma of Mental Illness: Implications for Self-Esteem and Self-Efficacy," Journal of Social and Clinical Psychology, 25 (8), 875-84.

Coulter, Robin. A., Linda. L. Price, and Lawrence. Feick (2003), "Rethinking the Origins of Involvement and Brand Commitment: Insights from Postsocialist Central Europe," Journal of Consumer Research, 30 (2), 151-69.

Crocker, Jennifer and Riia K Luhtanen (2003), "Level of Self-Esteem and Contingencies of SelfWorth: Unique Effects on Academic, Social, and Financial Problems in College Students," Personality and Social Psychology Bulletin, 29 (6), 701-12.

Cross, Samantha N.N. and Mary C. Gilly (2014), "Consumption Compromises: Negotiation and Unification within Contemporary Families," Journal of Business Research, 67 (4), 449-56. Debesay, Jonas., Dagfinn. Nåden, and Åshild. Slettebø (2008), "How Do We Close the Hermeneutic Circle? A Gadamerian Approach to Justification in Interpretation in Qualitative Studies," Nursing Inquiry, 15 (1), 57-66.

Elliott, Richard and Kritsadarat Wattanasuwan (1998), "Consumption and the Symbolic Project of the Self," European Advances in Consumer Research, 3, 17-20.

Featherstone, Mike (2010), "Body, Image and Affect in Consumer Culture," Body \& Society, 16 (1), 193-221.

Fehr, B. (2004), "Intimacy Expectations in Same-Sex Friendships: A Prototype InteractionPattern Model," Journal of Personality and Social Psychology, 86 (2), 265-84. 
Fredrickson, Barbara L, Tomi-Ann Roberts, Stephanie M Noll, Diane M Quinn, and Jean M Twenge (1998), "That Swimsuit Becomes You: Sex Differences in Self-Objectification, Restrained Eating, and Math Performance," Journal of Personality and Social Psychology, 75 (1), 269-84.

Fredrickson, Barbara L. and Tomi-Ann A. Roberts (1997), "Objectification Theory," Psychology of Women Quarterly, 21 (2), 173-206.

Giddens, Anthony (1991), Modernity and Self-Identity: Self and Society in the Late Modern Age, Cambridge Polity Press.

Gioia, Dennis A, Kevin G Corley, and Aimee L Hamilton (2013), "Seeking Qualitative Rigor in Inductive Research Notes on the Gioia Methodology," Organizational Research Methods, 16 (1), 15-31.

Gollwitzer, Peter M (1999), "Implementation Intentions: Strong Effects of Simple Plans," American Psychologist, 54 (7), 493-503.

Gulas, Charles S and Kim McKeage (2000), "Extending Social Comparison: An Examination of the Unintended Consequences of Idealized Advertising Imagery," Journal of Advertising, 29 (2), 17-28.

Gurrieri, Lauren, Josephine Previte, and Jan Brace-Govan (2013), "Women’s Bodies as Sites of Control Inadvertent Stigma and Exclusion in Social Marketing," Journal of Macromarketing, 33 (2), 128-43.

Hartman, Jessica D, Julie A Patock-Peckham, William R Corbin, Jonathan R Gates, Robert F Leeman, Jeremy W Luk, and Kevin M King (2015), "Direct and Indirect Links between Parenting Styles, Self-Concealment (Secrets), Impaired Control over Drinking and AlcoholRelated Outcomes," Addictive behaviors, 40 (January ), 102-08. 
Heidegger, Martin (2010), Being and Time, Trans. Stambaugh, Joan., Albany: State University of New York Press.

Helgeson, Vicki S., Phillip Shaver, and Margaret Dyer (1987), "Prototypes of Intimacy and Distance in Same-Sex and Opposite-Sex Relationships," Journal of Social and Personal Relationships, 4 (2), 195-233.

Higgins, E. T. (1987), "Self-Discrepancy: A Theory Relating Self and Affect," Psychological Review, 94 (3), 319-40.

Hilgard, Ernest R. (1949), "Human Motives and the Concept of the Self," American Psychologist, 4 (9), 374-82.

Hogg, Margaret K and Pauline Maclaran (2008), "Rhetorical Issues in Writing Interpretivist Consumer Research," Qualitative Market Research: An International Journal, 11 (2), 130-46. Hogg, Margaret K., Emma N. Banister, and Christopher A. Stephenson (2009), "Mapping Symbolic (Anti-) Consumption," Journal of Business Research, 62 (2), 148-59.

Holbrook, Morris B. and Elizabeth C. Hirschman (1982), "The Experiential Aspects of Consumption: Consumer Fantasies, Feelings, and Fun," Journal of Consumer Research, 9 (2), $132-40$.

Jack, Dana Crowley (1991), Silencing the Self: Women and Depression, Cambridge, MA: Harvard University Press.

Johnston, Josée and Judith Taylor (2008), "Feminist Consumerism and Fat Activists: A Comparative Study of Grassroots Activism and the Dove Real Beauty Campaign," Signs, 33 (4), 941-66.

Kaplan, Alexandra (1986), "The" Self-in-Relation": Implications for Depression in Women," Psychotherapy: Theory, Research, Practice, Training, 23 (2), 234-42. 
Küpers, Wendelin, Saku Mantere, and Matt Statler (2013), "Strategy as Storytelling a

Phenomenological Collaboration," Journal of Management Inquiry, 22 (1), 83-100.

Larsen, Randy J. (2000), "Toward a Science of Mood Regulation," Psychological Inquiry, 11 (3), $129-41$.

Larson, Dale G and Robert L Chastain (1990), "Self-Concealment: Conceptualization, Measurement, and Health Implications," Journal of Social and Clinical Psychology, 9 (4), 439-55.

Laurenceau, Jean-Philippe, Lisa Feldman Barrett, and Paula R Pietromonaco (1998), "Intimacy as an Interpersonal Process: The Importance of Self-Disclosure, Partner Disclosure, and Perceived Partner Responsiveness in Interpersonal Exchanges," Journal of Personality and Social Psychology, 74 (5), 1238-51.

Lemay Jr, Edward P., Margaret S. Clark, and Aaron Greenberg (2010), "What Is Beautiful Is

Good Because What Is Beautiful Is Desired: Physical Attractiveness Stereotyping as Projection of Interpersonal Goals," Personality and Social Psychology Bulletin, 36 (3), 33953.

Lerner, Jacqueline V, Christopher Hertzog, Karen A Hooker, Mahin Hassibi, and Alexander Thomas (1988), "A Longitudinal Study of Negative Emotional States and Adjustment from Early Childhood through Adolescence," Child Development, 59 (2), 356-66.

Lewis, Michael (1995), Shame: The Exposed Self, New York, N.Y.: Free Press. Lynch, Martin F (2014), "The Self-Concept in Relationships," in Human Motivation and Interpersonal Relationships: Theory, Research, and Applications, ed. Netta Weinstein, Dordrecht, Heidelberg, New York and London: Springer, 121-37. Lyubomirsky, Sonja, Laura King, and Ed Diener (2005), "The Benefits of Frequent Positive Affect: Does Happiness Lead to Success?," Psychological Bulletin, 131 (6), 803-55. 
Mashek, Debra J and Arthur Aron, eds. (2004), Handbook of Closeness and Intimacy, Mahwah, NJ:: Lawrence Erlbaum Associates.

Mauss, Iris B., Amanda J. Shallcross, Allison S. Troy, Oliver P. John, Emilio Ferrer, Frank H. Wilhelm, and James J. Gross (2011), "Don't Hide Your Happiness! Positive Emotion Dissociation, Social Connectedness, and Psychological Functioning," Journal of Personality and Social Psychology, 100 (4), 738-48.

Maxwell, Joseph A (1992), "Understanding and Validity in Qualitative Research," Harvard Educational Review, 62 (3), 279-301.

McCracken, Grant David (2008), Transformations: Identity Construction in Contemporary Culture, Bloomington, IN: Indiana University Press.

Mead, George Herbert (1934), Mind, Self and Society, Chicago: University of Chicago Press. Mead, Nicole L, Roy F Baumeister, Tyler F Stillman, Catherine D Rawn, and Kathleen D Vohs (2011), "Social Exclusion Causes People to Spend and Consume Strategically in the Service of Affiliation," Journal of Consumer Research, 37 (5), 902-19.

Moradi, Bonnie and Yu-Ping Huang (2008), "Objectification Theory and Psychology of Women: A Decade of Advances and Future Directions," Psychology of Women Quarterly, 32 (4), 37798.

Ogilvie, Daniel M. (1987), "The Undesired Self: A Neglected Variable in Personality Research," Journal of Personality and Social Psychology, 52 (2), 379-85.

Overton, P. G., F. E. Markland, H. S. Taggart, G. L. Bagshaw, and Jane Simpson (2008), "SelfDisgust Mediates the Relationship between Dysfunctional Cognitions and Depressive Symptomatology," Emotion, 8 (3), 379-85.

Piran, Niva and Holly C Cormier (2005), "The Social Construction of Women and Disordered Eating Patterns," Journal of Counseling Psychology, 52 (4), 549-58. 
Polkinghorne, Donald E (1991), "Narrative and Self-Concept," Journal of Narrative and Life History, 1 (2-3), 135-53.

Rawn, Catherine D., Kathleen D. Vohs. (2011), "People Use Self-Control to Risk Personal Harm: An Intra-Interpersonal Dilemma," Personality and Social Psychology Review, 15 (3), 267-89.

Richins, Marsha L. (1991), "Social Comparison and the Idealized Images of Advertising," Journal of Consumer Research, 18 (1), 71-83.

Ryan, Richard M and Edward L Deci (2001), "On Happiness and Human Potentials: A Review of Research on Hedonic and Eudaimonic Well-Being," Annual Review of Psychology, 52 (1), $141-66$.

Schouten, John W. (1991), "Selves in Transition: Symbolic Consumption in Personal Rites of Passage and Identity Reconstruction," Journal of Consumer Research, 17 (4), 412-25.

Scott, Linda M. (2006), Fresh Lipstick: Redressing Fashion and Feminism, New York: Palgrave Macmillan.

Stillman, Tyler F., Roy F. Baumeister, Nathaniel M. Lambert, A. Will Crescioni, C. Nathan DeWall, Frank D. Fincham. (2009), "Alone and without Purpose: Life Loses Meaning Following Social Exclusion," Journal of Experimental Social Psychology, 45 (4), 686-94. Stoppard, Janet (2014), Understanding Depression: Feminist Social Constructionist Approaches, Oxon and New York: Routledge.

Strelan, Peter and Duane Hargreaves (2005), "Women Who Objectify Other Women: The Vicious Circle of Objectification?," Sex Roles, 52 (9-10), 707-12.

Szymanski, Dawn M and Stacy L Henning (2007), "The Role of Self-Objectification in Women’s Depression: A Test of Objectification Theory," Sex roles, 56 (1-2), 45-53.

Thompson, Craig J. (1996), "Caring Consumers: Gendered Consumption Meanings and the Juggling Lifestyle," Journal of Consumer Research, 22 (4), 388-407. 
--- (1997), "Interpreting Consumers: A Hermeneutical Framework for Deriving Marketing Insights from the Texts of Consumers' Consumption Stories," Journal of Marketing Research, 34 (4), 438-55.

Thompson, Craig J. and Elizabeth C. Hirschman (1995), "Understanding the Socialized Body: A Poststructuralist Analysis of Consumers' Self-Conceptions, Body Images, and Self-Care Practices," Journal of Consumer Research, 22 (2), 139-53.

Thompson, Craig J., William B. Locander, and Howard R. Pollio (1989), "Putting Consumer Experience Back into Consumer Research: The Philosophy and Method of ExistentialPhenomenology," Journal of Consumer Research, 16 (2), 133-46.

Thompson, Craig J., Howard R. Pollio, and William B. Locander (1994), "The Spoken and the Unspoken: A Hermeneutic Approach to Understanding the Cultural Viewpoints That Underlie Consumers' Expressed Meanings," Journal of Consumer Research, 21 (3), 432-52.

Tian, Kelly. and Russell. W. Belk (2005), "Extended Self and Possessions in the Workplace," Journal of Consumer Research, 32 (2), 297-310.

Vogel, David L, Sarah R Heimerdinger-Edwards, Joseph H Hammer, and Asale Hubbard (2011), "“Boys Don't Cry”: Examination of the Links between Endorsement of Masculine Norms, Self-Stigma, and Help-Seeking Attitudes for Men from Diverse Backgrounds," Journal of Counseling Psychology, 58 (3), 368-82.

Yeager, David Scott and Carol S Dweck (2012), "Mindsets That Promote Resilience: When Students Believe That Personal Characteristics Can Be Developed," Educational Psychologist, 47 (4), 302-14. 
Table 1: Thematic structure emerging from informants’ self-presentation experiences

\begin{tabular}{|c|c|c|c|c|}
\hline 1st-order Concepts & $\begin{array}{l}\text { Strategy Narratives } \\
\text { (2nd-order Concepts) }\end{array}$ & $\begin{array}{l}\text { Wellbeing Challenges } \\
\text { (Aggregate Dimensions) }\end{array}$ & Illustrative Quotation & Literature \\
\hline $\begin{array}{l}\text { - Camouflage } \\
\text { - Discomfort/Anxiety } \\
\text { - Self-rejection } \\
\text { - Inferiority } \\
\text { - Rebellious } \\
\text { - Compensation } \\
\text { - Exposure }\end{array}$ & $\begin{array}{l}\text { Consumption is used to } \\
\text { avoid an undesired } \\
\text { shared experience by 1) } \\
\text { compensating or 2) } \\
\text { rejecting a specific self- } \\
\text { dimension }\end{array}$ & $\underline{\text { Self-Avoidance }}$ & $\begin{array}{l}\text { 1) "I had eczema as a child. Maybe that is a } \\
\text { camouflage on my makeup when I had } \\
\text { eczema. I remember having it and having to } \\
\text { wear these gloves...That was before I started } \\
\text { using the makeup, so maybe going down that } \\
\text { path and then thinking I look a lot better with } \\
\text { the makeup on." (Age 57, Cashier) } \\
\text { 2) "I've been brought up in a country where I } \\
\text { don't look like the majority of people. So I } \\
\text { always feel like a bit of outside the world...I } \\
\text { often wear extensions and I recently took } \\
\text { them out and he [my boyfriend] thinks it suits } \\
\text { me much better...but now I'm so used to } \\
\text { conforming and having straight hair. It } \\
\text { almost becomes so much a part of me. My } \\
\text { makeup is now almost part of me that even } \\
\text { though I know he likes me like that, I now } \\
\text { don't feel comfortable without it all on." } \\
\text { (Age 27, communications manager) }\end{array}$ & $\begin{array}{l}\text { Self-deception } \\
\text { (Hilgard 1949); } \\
\text { feelings of self- } \\
\text { disgust/loathing } \\
\text { (Overton et al. } \\
\text { 2008); shame \& } \\
\text { self-exposure } \\
\text { (Lewis 1995) }\end{array}$ \\
\hline $\begin{array}{l}\text { - Readiness } \\
\text { - Positive outlook } \\
\text { - Confidence } \\
\text { - Empowerment } \\
\text { - Daring/tougher/ } \\
\text { stronger } \\
\text { - Better engagement } \\
\text { - Being me }\end{array}$ & $\begin{array}{l}\text { Consumption is used to } \\
\text { facilitate a desired } \\
\text { shared experience by 1) } \\
\text { cheering up the self or 2) } \\
\text { empowering a specific } \\
\text { self-dimension }\end{array}$ & $\begin{array}{l}\text { Self-Advocacy } \\
\text { Challenge }\end{array}$ & $\begin{array}{l}\text { 1) "I've got no makeup on me and I feel very } \\
\text {.. relaxed and really not bothered to do } \\
\text { anything. If I have a bit of makeup on me and } \\
\text { I dress a little bit better... I feel as though I'm } \\
\text { ready for anything .... You just feel more } \\
\text { dressed, but if you don't wear makeup and } \\
\text { you're casual, you feel as though, for me, you } \\
\text { let things drift.” (Age 62, retired) } \\
\text { 2)“Confident [when I have got my makeup } \\
\text { on]. I can go anywhere...I can look anyone in } \\
\text { the face and I don't really care what they } \\
\text { think about me." (Age 29, school teacher) }\end{array}$ & 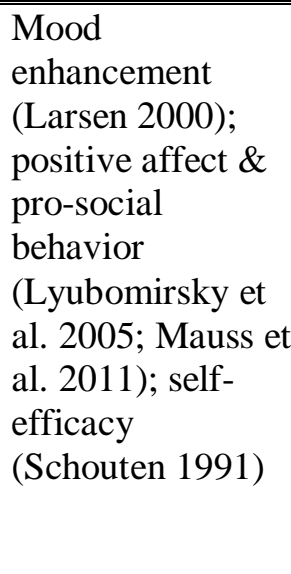 \\
\hline
\end{tabular}


- Thoughtfulness

- Caring

- Relationship enhancement

- Bonding/closeness

- Trust/acceptance
Consumption is used to create intimacy between parties by 1) caring for others or 2) bonding with others
Intimacy Challenge

1) "It's more about me at the moment whereas in the future if I have kids, then your priority changes. I think it is like once you are a mother, I think because you are a role model as well and kids look up to you. I want my kids to grow up with confidence that they are beautiful in the way they are naturally." (Age 30, investment analyst)

2) "My friends...we're all, in a sense, where we like make up, it is a bonding thing, like, we'll go and get our nails done...it's, like, what are you wearing, what make up are you having on, like, if you're going out for the evening, so, I have found friends and people that share my own interests, make up is an interest, to me." (Age 27, social worker)

\section{- Imitation}

- Timid

- Frightening experiences

- Pretence

- External threats

- Conformity

- Tricks

- Protection

Consumption is used to $\quad$ Survival Challenge
survive from an
otherwise difficult
circumstance by 1)
fitting in with others or
2) misleading others

1) "I went to quite a good school and we had the girls that were from the cool gang and they were all really well off...and they all had nice hair and they were all very thin and they wore make-up but in a really cool way...because you thought that if you wore make-up like them or if you had your hair like them you would make the impression to other people that you had the money like they did." (Age 20, receptionist)

2) "I would never ever going to work without makeup. I can't leave my house without any makeup on.... And I think everyone... would be shocked to see me without makeup on $\mathrm{Coz}$ they're so used to see me with that on. They think that I look like that anyway.” (Age 31, accountant)
Components of intimacy (Fehr 2004; Helgeson et al. 1987); intimacy \& selfdisclosure

(Laurenceau et al. 1998; Mashek and Aron 2004)

Social exclusion (Mead et al. 2011; Stillman et al. 2009); self control for personal harm (Rawn and Vohs 2011) 
Table 2: A matrix of strategy narratives for managing wellbeing challenges

\begin{tabular}{lll}
\hline \hline $\begin{array}{l}\text { Managing wellbeing } \\
\text { challenges }\end{array}$ & Dimension 1: Focus & \\
\cline { 2 - 3 } Dimension 2: Intention & Self focus & Other focus \\
\hline Concealing the negative self & $\begin{array}{l}\text { Self-Avoidance Challenge: } \\
\text { Consumption is used to } \\
\text { avoid an undesired shared } \\
\text { experience by } \\
\text { compensating or rejecting } \\
\text { a specific self-dimension }\end{array}$ & $\begin{array}{l}\text { Survival Challenge: } \\
\text { Consumption is used } \\
\text { to survive from an } \\
\text { otherwise difficult } \\
\text { circumstance by } \\
\text { fitting in with others } \\
\text { or misleading others } \\
\text { Intimacy Challenge: }\end{array}$ \\
& $\begin{array}{l}\text { Self-Advocacy Challenge: } \\
\text { Enhancing the positive self } \\
\text { facilitate a desired shared } \\
\text { experience by cheering up } \\
\text { the self or empowering a } \\
\text { specific self-dimension }\end{array}$ & $\begin{array}{l}\text { Consumption is used } \\
\text { to create intimacy } \\
\text { between parties by } \\
\text { caring for others or } \\
\text { bonding with others }\end{array}$ \\
\hline
\end{tabular}


Figure 1: The emergence of personal wellbeing from managing the self in social relationships

\section{Dimension 2: Consumption intention}

An incongruous pathway, focusing on enhancing the positive self in social interactions

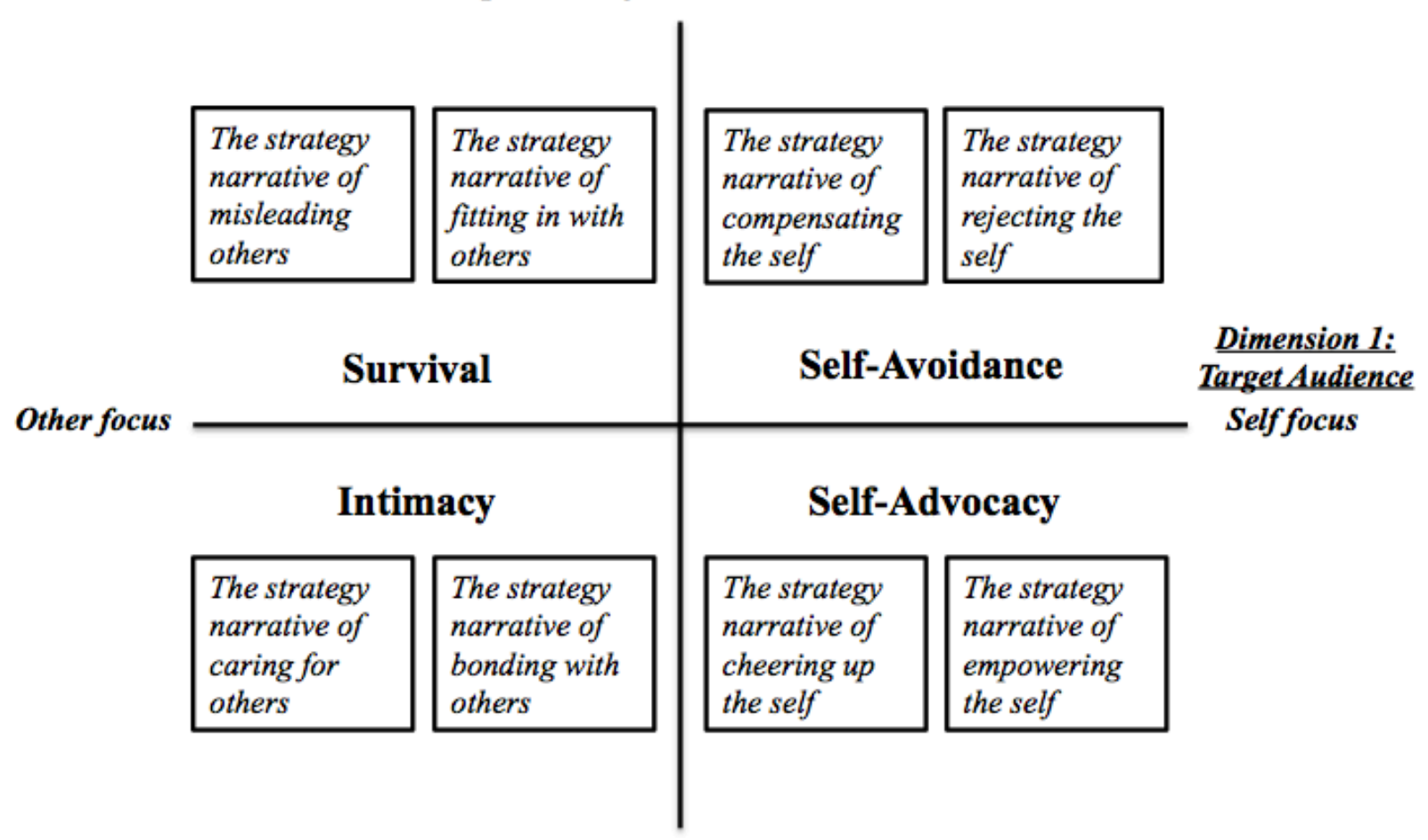

A harmonious pathway, focusing on concealing or transforming the negative self in social interactions 